\section{Variation in the Ratio of Strontium-89 to Strontium-90 in Precipitation Samples with Sampling Height}

IT was shown that during March-December 1959 (ref. 1) the specific activities of fission products from fall-out in precipitation increased with sampling height. Some evidence was also found for an increase in the ratio ${ }^{89} \mathrm{Sr} /{ }^{80} \mathrm{Sr}$ with sampling height, but this increase was not significant $(P \sim 90$ per cent). (where $y$ is the transformed ${ }^{89} \mathrm{Sr} /{ }^{80} \mathrm{Sr}$ ratio, and $x$ is the sampling height).

An analysis of variance showed significant differences between the slopes for dry and wet months for both group I ( $P \sim 99$ per cent) and group II $(P>99$ per cent) (Tables 2 and 3 ).

Hence, it is evident that in 'dry' months the slope was significantly steeper than in the 'wet' months, that is, the ${ }^{89} \mathrm{Sr} /{ }^{90} \mathrm{Sr}$ ratios in 'dry' months were significantly higher in the upper precipitation collectors than in the lower. An

Table 1. RATIO OF STRONTIUM-89 TO STRONTIOM-90 IN PRECIPITATION COLLECTED AT EIGHT DIFFERENT HEIGHTS IN THE PERIOD OOTOBER, 1961-SEPTEMBER, 1963

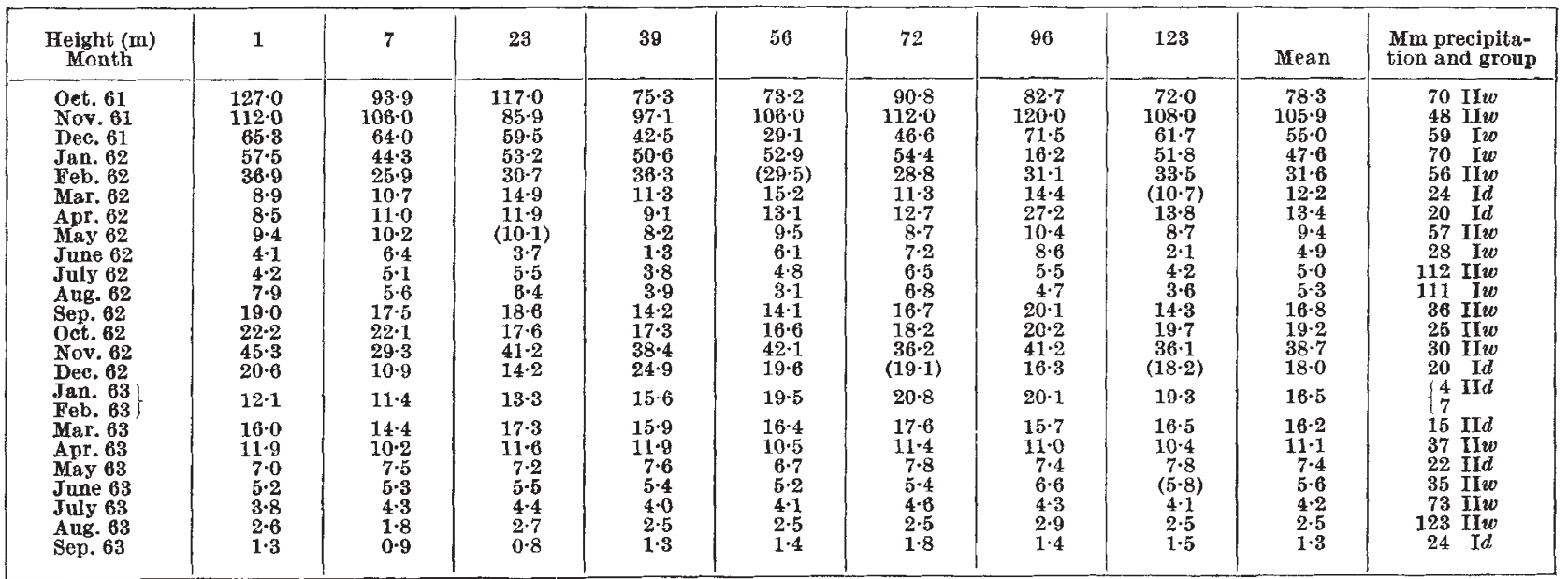

Figures in brackets are missing values calculated by the method of least squares. These figures are omitted in the regression analysis.

Table 2. Comparison of the LINes in Group I ANaLysis of Variance

\begin{tabular}{|c|c|c|c|c|}
\hline Variation & $\begin{array}{l}\text { Sum of squares } \\
\text { of deviations }\end{array}$ & $\begin{array}{l}\text { Degrees of } \\
\text { freedom }\end{array}$ & Variance & Test \\
\hline $\begin{array}{l}\text { about lines } \\
\text { between slopes }\end{array}$ & $\begin{array}{c}0.4147 \\
0.5045 \times 10^{-3}\end{array}$ & $\begin{array}{r}57 \\
1\end{array}$ & $\begin{array}{l}0.7275 \times 10^{-1} \\
0.5045 \times 10^{-1}\end{array}$ & 6.94 \\
\hline
\end{tabular}

Table 3. Comparison of the Lines in Group II. ANalysis of Variance

\begin{tabular}{lcccc}
\multicolumn{1}{c}{ Variation } & $\begin{array}{c}\text { Sum of squares } \\
\text { of deviations }\end{array}$ & $\begin{array}{c}\text { Degrees of } \\
\text { freedom }\end{array}$ & Variance & Test \\
about lines & $0.7378 \times 10^{-1}$ & 114 & $0.6472 \times 10^{-s}$ & \\
between slopes & $0.4952 \times 10^{-2}$ & 1 & $0.4952 \times 10^{-2}$ & $7 \cdot 65$
\end{tabular}

After the resumption of large-scale nuclear testing in September 1961 , it became possible to repeat the experiment over a longer period. The ${ }^{89} \mathrm{Sr} /{ }^{90} \mathrm{Sr}$ ratios were determined in precipitation collected at eight different heights in the meteorological mast at Risö after the principles used in 1959 (ref. 1).

Table 1 shows the results for the 24-month period: October 1961-September 1963.

The ${ }^{89} \mathrm{Sr} /{ }^{90} \mathrm{Sr}$ ratios in Table 1 were treated as follows. The ratios were converted to the logarithms, because the figures were logarithmically distributed. The converted ratios for each month were divided by the corresponding (converted) mean ratio for the month. The purpose of this operation was to eliminate the effect of the time variation of the ${ }^{89} \mathrm{Sr} /{ }^{00} \mathrm{Sr}$ ratios. The months were separated into two groups, one with high variance $(I)$ and one with low (II). This was necessary for the performance of a regres. sion analysis, where the differences in the variances have to be insignificant. The two groups of months were each sub-divided into two sub-groups, one representing 'dry' month $(d)$, that is, months with less than $25 \mathrm{~mm}$ precipitation and another representing 'wet' month $(w)$, that is, months with $25 \mathrm{~mm}$ and more precipitation (Table 1).

The following regression lines were calculated:

$$
\begin{aligned}
& y=1+0.1040 \times 10^{-2}(x-46 \cdot 55) \\
& y=1-0.4452 \times 10^{-3}(x-52 \cdot 13) \\
& y=1+0.4050 \times 10^{-3}(x-52 \cdot 13) \\
& y=1+0.6857 \times 10^{-5}(x-52.39)
\end{aligned}
$$

explanation for this phenomenon has been proposed earlier ${ }^{1}$ : it is assumed that the dry deposit, which yields the higher concentrations in the upper precipitation collectors, is of greater particle-size than the deposit from rain. Larger and heavier particles will be deposited more readily than fine particles, and consequently the coarse particles will consist of younger fission products (greater ${ }^{89} \mathrm{Sr} /{ }^{00} \mathrm{Sr}$ ratio) than the fine ones.

I thank Mr. Heinz Hansen for his advice concerning the statistics.

A. Aarkrog

Health Physics Department,

Danish Atomic Energy Commission,

Research Establishment, Risö, Roskilde.

${ }^{1}$ Aarkrog, A., Nature, 188, 482 (1960).

\section{Equivalence of the Schroedinger and Heisenberg Pictures}

IN a recent re-examination ${ }^{1}$ of the foundations of quantum mechanics, Dirac asserts, inter alia, that the Heisenberg and Schroedinger pictures in quantum electrodynamics are not equivalent because the unitary operator which connects both pictures, namely $e^{i H t / \hbar}$, where $H=H_{\text {Dirac field }}+H_{\text {Maxwell fleld }}+H_{\text {interaction, }}$, is the total Hamiltonian in the Schroedinger picture, does not exist. It is the purpose of this communication to question this assertion.

It is assumed from the outset that $H$ is, in common with all observables in quantum mechanics, self-adjoint;

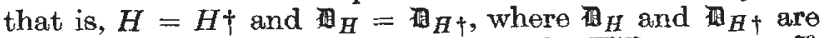
the domains of $H$ and its adjoint in the Hilbert space of the system. Accordingly, if $\{E(\lambda)\}$ are the projectors comprising the resolution of the identity belonging to $H$ and if $F(\lambda)$ is an arbitrary complex-valued function of $\lambda$, then the operator $F(H)$, with the domain $\mathbb{Z}_{F}$, is defined ${ }^{2}$ by the Radon-Stieltjes integral: 